\title{
SWELLING PRESSURES OF SOOIUM MONTMORILLONITE AT DEPRESSED TEMPERATURES
}

R. Yong, L.O. Taylor, and 6.P. Workentin

Soil Mechanics Series No. 4

Septembor, 1962

\section{SOIL MECHANICS LABBORATORY}

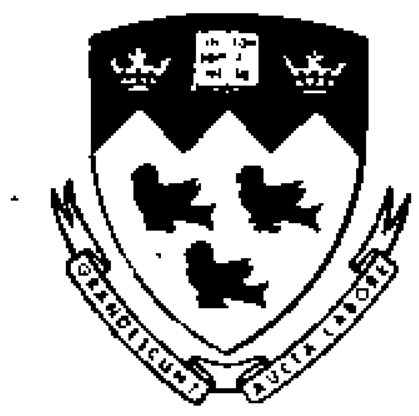

MCGILL UNIVERSITY

DEPARTMENT OF CIVIL ENGINEERING AND APPLIED MECHANICS 


\section{PREFACE}

The research work reported in this paper was perlormed under a continuing research grant from the Defence Research Board, in the form of a Grant-in-Aid of Research to Dr. Raymond Yong (Grant No. $9511-28$ (G. \& C.)). The Grant was first given in Apr1l 1958 with subsequent yearly renewals.

The authors wish to acknowledge their indebtedness to the Defence Research Board for its support and interest - without which this research study would not have been possible. This paper. prepared for presentation at the Eleventh National Clays and Clay Mine rals Conference in Ot tawa, concerns itself primarily with a study of the swelling pressures of a pure clay arising trom temperature depression. This is considered basic to the understanding of the phenomenon of frost heaving and soil freezing.

\section{Raymond Yong}

Asqociate Prolessor and Director.

Soil Mechanics Laboratory 
SWELLING PRESSURES OF SODIUM MONTMORILLONITE AT DEPRESSED T EMPERA TURES

by

R. Yong, L. O. Taylor, and B. P. Wa rkentin

Paper prepared for presentation at

Eleventh National Clays and Clay Minerals Conference

Ottawa, August, 1962

Soil Mechanics Laboratory

Department of Civil Engineering and Applied Mechanics

McGill University, Montreal 


\title{
SWELLING PRESSURES OF SODIUM MON'TMORLLLONITE
} AI DEPRESSED TEMPERATURES

\author{
by

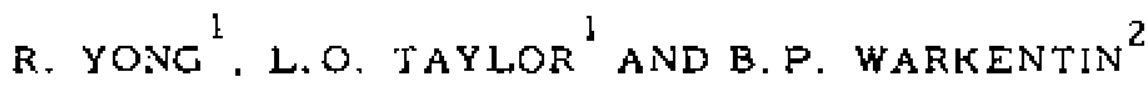

\section{ABSTRACT}

Swelling pres alures of oriented samples of sodium-montmorillonite at pore-water salt concentration of $10^{-4}$ and $10^{-2} \mathrm{M} \mathrm{NaCl}$ were mea eurtd at rontrolled temperatures ranging irom $1^{\circ} \mathrm{C}$ to $23^{\circ} \mathrm{C}$. The specially designed apparatus allowed swelling against a movable pi ston connected to a mercury manometer through which the ambient pressure was applied.

Calculations from the combined Foisson-Boltamann equation. taking the variation of temperature and dielectric constant into account. showed a decrease in swelling presure with decrease in temperature At a pore-water salt concentration of $10^{-4} \mathrm{M} \mathrm{NaCl}$, the meagured swelling pressure at 120 A average interparticle distance decreased from 48 cans. of mercury at $23^{\circ} \mathrm{C}$ to $35 \mathrm{cms}$, at $1^{\circ} \mathrm{C}$, while the corresponding calculated presiure decrease was from 48 to $40 \mathrm{cma}$. While the mea wred pressures fell below calculated values at higher distances, the influence of temperature remained consistent.

1. Soil Mtchanias Laboratory. McGill University, Montreal.

2. Soil Physich Laboratory, Macdonald College of McGill University. 
At $10^{-2} \mathrm{M} \mathrm{NaCl}$, the meatured sw:lling pressures were much higher than those predicted from the equation Corretiong based upon the effective salt concentrations requirtd by the thoty to give thr: experimentally meagured swelling presures at room temperitura were calculated. The se we re subatituted into the approximate Langmuir solution of the combined Poision-Boltzmann equation to describu the swelling pressure at $10^{-2} \mathrm{M}$ NaCl. With this cortection, the calculated swelling presaure at 120 A average interparticle distance decredied from $30 \mathrm{cms}$. at $23^{\circ} \mathrm{C}$ to $26 \mathrm{cms}$ at ${ }^{\circ} \mathrm{C}$ while the measured pressure decreased from 30 to $23 \mathrm{cms}$. This close agrtement betwan corrected calculated pressure and measured preseure held from 100 to $250 \mathrm{~A}$ interparticle spacing.

\section{ACKNOWLEDGEMENT}

The authora wish to express their appreciation to the Defence Resezrch Board of Canadit for the Grant-in-Ald of Resoarch which provided funds for the support of this study. 


\section{INTRODUCTION}

Measurements of bwelling pressure of clays baturated with sodiun ions at normal room temperature have been reported in previous studies by many investigators (e.g. Warkentin et al, 1957, Blackmore 1958, Warkentin and Schoileld, 1958). In general, good agreement has been found between measured values and theoretiral swelling preasures computed on the basis of adaption of the Gouy-Chapran theory of the diffuse double layer. In this instance, the combined Poisson-Boltzmann equation deacribing the concentration of ions at the midplane of two parallel cha rged plates is used to compute the van't Hoff prefisure arising frotn ion concentration difference between the midplane and the burrounding port-water golution. With the asumption of idtal behavior of ions, the van't Hoff pres gure may then be taken a the computed swelling pressure. Inastruch as the laboratory specimens correspond to the model used in the theoretical analysis, a fair degree of correspondence is maintained between measured and calculated swelling pressures.

The solution by Verwey and Overbek $(1948)$ for the PoissonBoltzmann equation for the case of overlapping diffuse double layers arising from close proximity of adjacent parallel charged plates gives:

$$
M x_{c}-2 \exp \left(-\gamma_{c} / 2\right) \int_{0}^{\pi} \frac{d \phi}{\sqrt{1-\exp \left(-2 \gamma_{4}\right) \sin ^{2} \phi}}
$$

where

$$
\begin{aligned}
& M=\sqrt{\frac{9 \pi x^{2} e^{2} n^{2}}{E k t}} \\
& Y_{e}=\frac{-z e \psi}{k T} \text { at midplane } \\
& \sin ^{2} \phi=\exp (-\gamma) / \operatorname{erp}\left(-\gamma_{a}\right)
\end{aligned}
$$




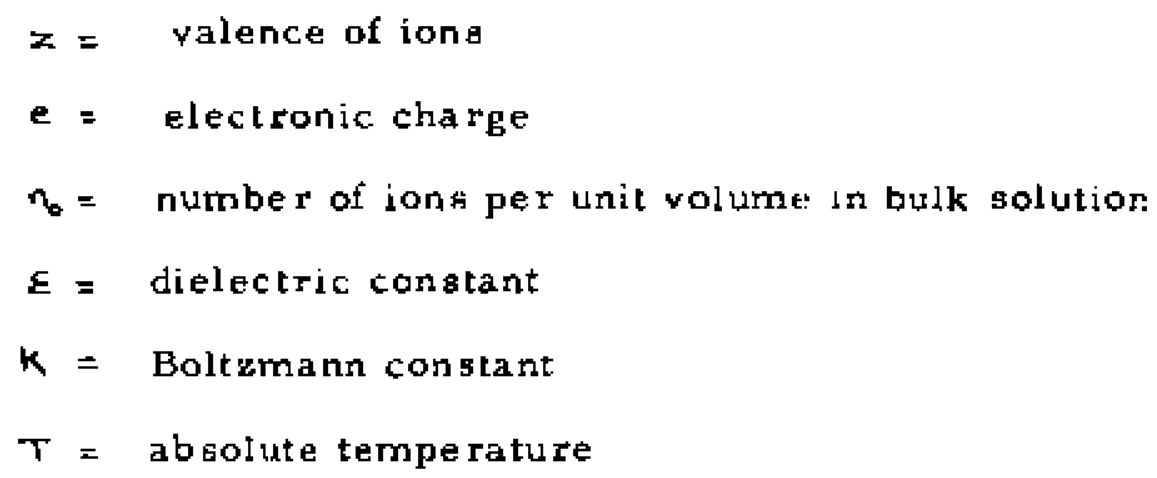

By using the Langmuir approximation which assumes that it is possible to neglect the prosence of ions carrying the same sign as the chargu on the plate, a simplified solution for $\Psi_{c}$ the midplane potential may bet derived..

$$
\psi_{c}=\frac{2 k T}{2 E} \ln \left(\frac{M x_{L}}{\hbar}\right)
$$

$$
\text { valid only for } Y_{c}>1
$$

Altematively, $\psi_{c}$ may also be obtained by summating the potentials due to single particles. In this instance:

$$
\psi_{c}=-\frac{4 k T}{z e} \ln \left(\operatorname{coth} \frac{M k_{c}}{k}\right)
$$

The van't Hofi equation (Schofield, 1946) may then be witten a

$$
P=2 K T n_{0}\left(\cosh \frac{2 \psi_{e}}{K T}-1\right)
$$

where $P=$ forcc per unit area required externally to keep adjacent - particles at a spacing of $2 x_{c}$

It is then possible to determine from the phy gical equations the effects of such variables as ionic concentration, valence, and temperature of the pore-water phase of an oriented clay-water system on resultant soil-water interaction.

Thesc equations suggest that a decrease in temperature would 
cause a compreasion of the double layer thus resuling in a decrease in osmotic swelling for the Hame interparticle spacing. Assuming that the conditions governing the ideal behaviour of the ione in the double layer are met reasonably well in the laboratory model, it would thus be possible to measure swelling preasure both as a function of temperature and interparticle distance. The conditions necessary for good afreement between meatured valuea and computed swelling preseures at room temperature must evidently be satisfied: i.e. (1) clay particles muat be plate shaped with lateral dimensions far exceeding their thickness, (2) Farticle sizes must be within the colloidal range and their euriaceg free from irregularities, (3) the assumption that the surface charge of the particle is of conatant sign (negative) and uniformly distributed should be rea gonably correct, (4) particle 9 must be homoionic and free (rom impurities, (5) particles muat be oriented parallel to each other, (6) the pore-water solution should consist of univalent ions of a aingle species (NaCl in this instance), and (7) the resulting clay-wate s sytem should be homogeneous. Approximate expressions accounting for the influence of dielectric saturation, polarization of ions, and ionic interactions in the structure of the electric double layer have been incorporated in the generalized Poisson-Boltzmann equation (Bolt, 1955), which resolves into a correction function. This correction function when applied to the Gouy-Chapman treatment of the electric double layer show that in the case of low concentration of co-ions in colloidal suspensions, the corrections involved are small if the surface charge dengity does not exceed $2 \times 10^{-7} \mathrm{~m}$. eq. $/ \mathrm{cm}^{2}$. 


\section{EXPERIMENTAL PROCEDURE}

Variation in swelling pressure arising from temperature depression can be obtained by firtat allowing samples of a well oriented clay-water system to attain their respective equilibrium volumes for specific values of applied pressure fwithin a predetermined pressure range), and either:

a. maintaining each equilibriun volume constant while lowering the temperature of the sample by predetermined increments. The pressure required to maintain the equilibrium volume for each temperature increment may then be measured to determine pressure change with temperature at constant volume or

b. maintaining the applied pressure constant while lowering the thmperature of the sample by predetermined increments. The resulting volume change that occurs under constant applied pressure for each temperature increment may then be determined.

The apparatus designed to accomodate either of the two methods proposed is shown in Figurey 1 and 2 . This consisted of a plexiglass chamber enclosed in an insulating box to restrict heat transfer with the external surroundings. Within the plexiglass chamber, an agitator kept the fluid in the constant temperature bath circulating both a round the cooling coils and the swelling thamber. The details of the swelling chamber ituelf is given in Figure 2 and the measurement system used 1s detailed in Figure 3. Temperature measurements within the swelling 
ing chamber were made by mearis ol a copper-constantin the rmo-touple whach passed through the rubber O-ring at the top and sat at the lace of the porous stont. A Leeds Northrup type No. 8662 potantionator was used in conjuntion with the the rmo-couple. The junction of thu th"rmo-couple luads was protected by several coats of tpoxy risin to prevent reaction with the pore-water solution.

Thr: systern of measurement for volume change within the swelling chamber consisted of a mercury piston conneted in such a way Lhat it could both exert a pressure on the stanless steel piston, and also measure volume changes of the test sample. The stainlas stuel pistor with an embedded porous stone provided a lavel fack with the sample and eliminated meniscus effects of the nutcury tace in the chambcr. Mercury was not expected to slip past the sides of the phston under pressure since the pressure differential as ross the face of the pistor was zero. In the event that slippage of mercury octurred because of the tole rance limits between wall and piston, no detrimental effects were expected. Mercury in diruct contuct with samples of pure clay was used successfully by IJemwall and Low (1956) in previous measure Inerts of swelling pressure.

In Figure 3, tha hatyy lines indicate the portion of the measurement system saturated with mercury and connected such that any change of volume occurring in the chamber as a result of pressure change is indicated by a corresponding change in the level of mercury in Column (2). The ratio of the cross-sectional area of the chamber to that of Column (2) is such that a small volume change of the sample in the swalling 
chamber causes a large change in the measuring column. This allows for an accurate measurement of minute voluma changes. Ambient pressures applied to the samples were measured effectively by a mercury manometar through the connection between the compressed ais cylinder and Column $(2)$.

In order to reduce the sensitivity of the apparatus to amall leaks that may develop thus causing a rapid loss of pressure, and at the same time to increase the volume of the system, an empty air cylinder was incorporated into the system. By slowly releasing air through valves (F) and (G) (shown in Figure 3), it was possible to obtain a gradual expansion of the sample. A more gradual expansion of the sample was obtained through valve (D) by partly filing the ait cylinder with oil and slowly bleeding the oil through valve (D). The loss of oil caused a decrease in pressure and allowed the sample to swell.

Oriented specimens of homoionic sodium-montmorillonite were prepared by slow sedimentation and drying of weak suspensions of the purtied clay. The clay suspensions which contained le th than one percent by weight of mate rial were allowed to settle olowly in small plexiglass tubes which were sealed at the bottom with cellophane membranes. This technique of slow evaporation and sedimentation whtch produced waferlike clay plates has been used successfully previously (Warkentin and Scholield, 1958).

Eive clay plates were placed individually in the flooded swelling chamber in the portion between the stainless steel piston and the top of the chamber. Milliport membranes were used at the faces of 
the top and bottom porous stones. Following sample immersion in the chamber and with both cap replaced and system de-aired, the sample was allowed to swell under a onall prescure restraint. Since the applied pressure was transmitted through tha mercury piston which also served as a scale for volume change measurements (shown in Figure 3 as the line passing through valve $C l$, initial zero readings for equilibrium volume at room temperature and initial pressure restraint could be made before introduction of the cooling fluid. A period of Irom three to six days was required to allow the sample to swell and come to equilibrium volume at room temperature. Tho length of time involved depended upon the initial pressure retitraint. The entire system was calibrated for temperature effects previous to test measurements. With this system, a predetemined initial pressure could be applied and following equilibrium conditions, a saries of resultant volume change $s$ might be measuredas a fumtion of lemperature depression. A complete test series on any one ample consisted of measurement of volume changes occurring as a result of temperature variation from $23^{\circ} \mathrm{C}$ to $1^{\circ} \mathrm{C}$ for a range of applied pressures. Since sample area is constant, volume changes can be reported as changes in interparticle spacing with a simple conversion. In Figures 4 and 5 the variation in interparticle spacing resulting from temperature depression under prescribed constanl applied presures has been shown for three complete series at $10^{-4} \mathrm{M} \mathrm{NaCl}$ pore-water balt concentration, and for one complete feries at $10^{-2} \mathrm{M} \mathrm{NaCl}$. 


\section{RESULTS AND DISCUSSION}

Swelling pressure measurements for both $10^{-4} \mathrm{M} \mathrm{NaCl}$ and $10^{-2} \mathrm{M} \mathrm{NaCl}$ samples have been plottcd in Figure 6 for the test series at $23^{\circ} \mathrm{C}$. The correspondence between measured valueb and computed swelling pressure indicated by the solid line for pore-water salt concentration of $10^{-4} \mathrm{M} \mathrm{NaCl}$ justifies uge of both techrique and apparatus. For $10^{-2} \mathrm{M}$ NaCl pore-water salt concentration, the measured values a re consistently higher than would be predicted from the physical equations. This is expected since the Boltzmann and van't fiof equations become lesa valid with increasing electrolyte concentration. At concentrations leas than $10^{-3} \mathrm{M} \mathrm{NaCl}$, the agreement between experimental values and computed suelling pressures indicate that the error involved in calculating oamotic pressure by the numerical difference is not large (Warkentin and Schofield, 1962). At higher conccentrations however, the error due to substitution of ionic concentrations Ior ionic activities becones more significant.

While effort to allow for ionic activity in double layer calculaLons have been made by Loeb (1951) and Bolt (1955), it does seem that because of the difficulties involved in determination of activity coefficiente for counter-ions between adjacent clay plates, calculation of corrected osmotic pressure based upon ionic activities is not possible. A more expedient method for correction of ommot ic presture at higher electrolyte concentration would be to determine the effective pore-water salt concentration required by theory to give experimentally measured 
swelling pressures.

From the Poiston-Boltzmann equation, the electric potential at the midplane $\psi_{c}$ may br: written as

$$
\psi_{c}=-\frac{2 k T}{z e} \ell_{n}\left(\frac{\pi}{\sqrt{5} M \times_{c}}\right)
$$

without altering the assumptions of the Gouy-Chapman theory bignificantly. Writing the van't Hoff equation as

$$
\psi_{c}=-\frac{K T}{z e} \cosh ^{-1}\left(\frac{P}{2 K \operatorname{Ts} n_{0}}+1\right)
$$

where

$$
\begin{aligned}
& S=\text { coefficient of effective salt concentration } \\
& S n_{0}=n^{*}=\text { effective salt concentration }
\end{aligned}
$$

the effective pore-water salt concentration which produces the same value for $\psi_{c}$ in equations (5) and (6) may then be determined, For $10^{-4} \mathrm{M}$ NaCl concentration, very little correction if any is needed. For $10^{-2} \mathrm{M} \mathrm{NaCl}$ concentration, thi g presuppose日 that the experimentally determined values are correct. The relationship defined for the effective salt concentration based upon equating the midplane potentials shown in equations (5) and (6) and measured swelling presaures for $10^{-2} \mathrm{M} \mathrm{NaCl}$ indicale that the effective salt concentration would be dependent on interparticle spacing.

The method of solution of the effuctive pore-water galt concentration for the $10^{-2} \mathrm{M} \mathrm{NaCl}$ sample consisted of detemining the midplane potential for each of the measured values of awelling pressure from equatıons (4) and (2) using varying values of pore-water salt concentrations. For any one effective pore-water salt concentration, the value 
of the electric potential obtained from equation (4) must equal that obtained from equation (2). The refore, tor each chosen concentration, the algebraic differences in the mid-plane potentials were calculated from equations (4) and (2) for each ambient prosure. The relationship botween algebraic differenct in mid-plane potential and pore-water galt concentration may then be established for any chosin value of swelling pressure. The equation established the reby showing variation in the effective pore-water salt concentration with half distance gives:

$$
s x_{c}=\frac{x_{c}^{2}}{244}-0.77 x_{c}+60.7
$$

ith temperature and dieltctric constant variation, thr theoretical equation may then be modififd with the use of equation (7).

Based upon measurements shown in Figur*s 4 and 5 , the vari = ation of swelling presaure as influenced by temperature depresion may then be drawn - as shown in Figures 7 and 8 . The effect of a variable dielectric constant is considered in Figure 8 . The relationship establi ghed by Sirvastava and Varhi (1956) for a variable dielectric constant was used in calculating variation of $\varepsilon$ with temperature.

$$
E=\frac{62445}{T+120}-70+91
$$

The dielectric constant was assumed to be that of the solvent. While it it recognised that the dielectric constant of the water phase in clay soils and of adsorbed water may be bignificantly different (Pickett and Lemcoe 1959, Muir 1954), the assumptions involved in the initial equations of the Gouy-Chapman theory dictate the use of the solvant value for the 
dielectric constant.

The correspondence between predicted values and measuled swelling pressures for the $10^{-2} \mathrm{M} \mathrm{NaCl}$ sample shows the validuty of the use of the effective salt concentration for correction. As seen from the graphs, there is reasonably close agreement between swelling prusures and calculated values for smaller interparticle spacings for the $10^{-4} \mathrm{M} \mathrm{NaCl}$. While measured pressuros at higher spacings fell below the calculated values, the influence of temperature on swelling pressure remained consistent.

In accordance with theoretical predictions, measured values of awclling presaure decreased with decreasing temperatures, The physical model of the elcctric double layer assurnes that a large portion of its magnitude is derived from the the rmal energy of the ions which tend to restrict orientation in the field of charged plates, thus causing the - Lectric doublc layer to extend over large disinces from the charged surface. It is expected that if the thu rmal energy of the ions is decreased, the capacity of the ions to resist oricntation will decrease, and accordingly, the thickness of the electric double layer will also decrease. While the temperature depression decrate日 the tharmal energy of the ions, the dielectric constant on the other hand will increase, whith in turn would tend to cause the thickness of the electric double layer to incre a se. The net uffect however is a decrease in electrc double layer thicknes since the re is evidence that the clfect of a decrease in thit rmal energy is greater than that of the dielectric constant. Moreover, as the temperAture $1 \mathrm{~s}$ d'pressed, the concentration and distribution of ions in gencral 
will decrease correspondingly, and a further decrease in the electric double layer may then be expected on the basis of reduction of effective volume.

The divergence of measured values from calculated swelling pressures for $10^{-4} \mathrm{M} \mathrm{NaCl}$ samples at higher interparticle spacings under room temperature conditiong has been pointed out in a previous study ( $Y$ ong and Warkentin 1959). However, the close agreement between mea sured and calculated values for swelling pressure shown in the case of the $10^{-2} \mathrm{M} \mathrm{NaCl}$ sample, suggestu that correction for effective porewater salt concentration for the $10^{-4} \mathrm{M} \mathrm{NaCl}$ samples at higher interparticle spacings may be necessary. If a similar correction is made for the $10^{-4} \mathrm{M} \mathrm{NaCl}$ samples for effective pore-water galt concentration at lower ambient pressurea, as in the case of the $10^{-2} \mathrm{M} \mathrm{NaCl}$ sample carried over its entire range of pressures, better agreement would be achieved under depressed temperature conditions.

While the use of the effective pore-water salt concentration serves to adjust the physical equations to conform with initial measured values, it does not explain the reasons for the consistent differences between measured and calculated values. The reasona for the differences are not quite clear, but they are thought to lie partially in the limitations of the double layer theory, the lack of particle orientation at higher interparticle epacings and probably in the pos aible impurities in the clay. 


\section{CONCLUSIONS}

Consistent with theoretical predictions, measured value 8 of ewelling pressure dec reased with temperature depression. With the wse of a correction expressed in terms of the effective pore-water falt concentration, the approximate Langmuir solution of the combined Poisson-Boltzmann equation may be used to describe swelling pressure of sodium montmorillonite within certain restricted limits. The magnitude of the decrease in swelling pressure under predeterminod interparticle spacings ariging from temperature changes (between $23^{\circ} \mathrm{C}$ and $1^{\circ} \mathrm{C}$, in the preasure range of 0.1 to 1.0 atmospherea may be adequatuly predicted from double layer calculations. 
Blackmore, A, V. $\{1958\}$. The swelling pressures of homoionic montmorillonites saturated with monovalent cation of the lyotopic series: M.S. thesis, Cornell Univereity.

Bolt, G.H. (1955). Analysis of the validity of the Gouy-Chapman theory of the electric double layer: Journal Colloid Science, V. 10, pp. 206.

Hemwall, $J$, and Low, P. (1956). The hydrostatic repulsive force in clay swelling: Proc. Soil Sci.Soc. V. 20

Loeb. A. (1951). An interionic theory applied to the diffuse laye $\mathrm{r}$ a round colloid particles: Journal Colloid Science. V.6, pp.75-9l

Muir, J. (1954). Dielectric loss in water filma adsorbed by gilicate clay mineral a: Transfar.Soc. V.50, pp.249-254.

Pickett, A. and Lemcoe, M. (1959). An investigation into the ghear strength of clay-water system by radio frequency spectroscopy: Jour.Geophys. Res. V.64, Pp. $1579-1585$

Sirvastava, V. and Varshni, P. (1956). Variation in dielectric constant with temperature; Physica V.22.

Verwey, E. and Overbeek, $5,(1948)$. Stability of lyophobic colloids Elesvier, Amsterdam.

Warkentin, B.P., Bolt, G.H., and Miller, R.D. (1957). "Swelling pressure of montmorillonite: Proc.Soil. Sci.Soc.Am. V, 2L, No, 5, pp. $495-497$

Warkentin, B.P. and Schofield, R. (1958). Swelling presoure of dilute sodium-montmorillonite pastes: Proc. 7th Nat. Conf. Clays and Clay Min. pp. 343-349

Warkentin, B.P. and Schofield, R. (1962). Swelling pressure of sodium montmorillonite in $\mathrm{NaCl}$ solutions: paper for Faraday Society

Yong, R. and Warkentin, B.P. (1959). Physico-chemical analysis of high swelling clays aubject to loading: First Pan. Am. Conf. Soil Mech. and Found. Engr. V. 2, Pp. 865-888 


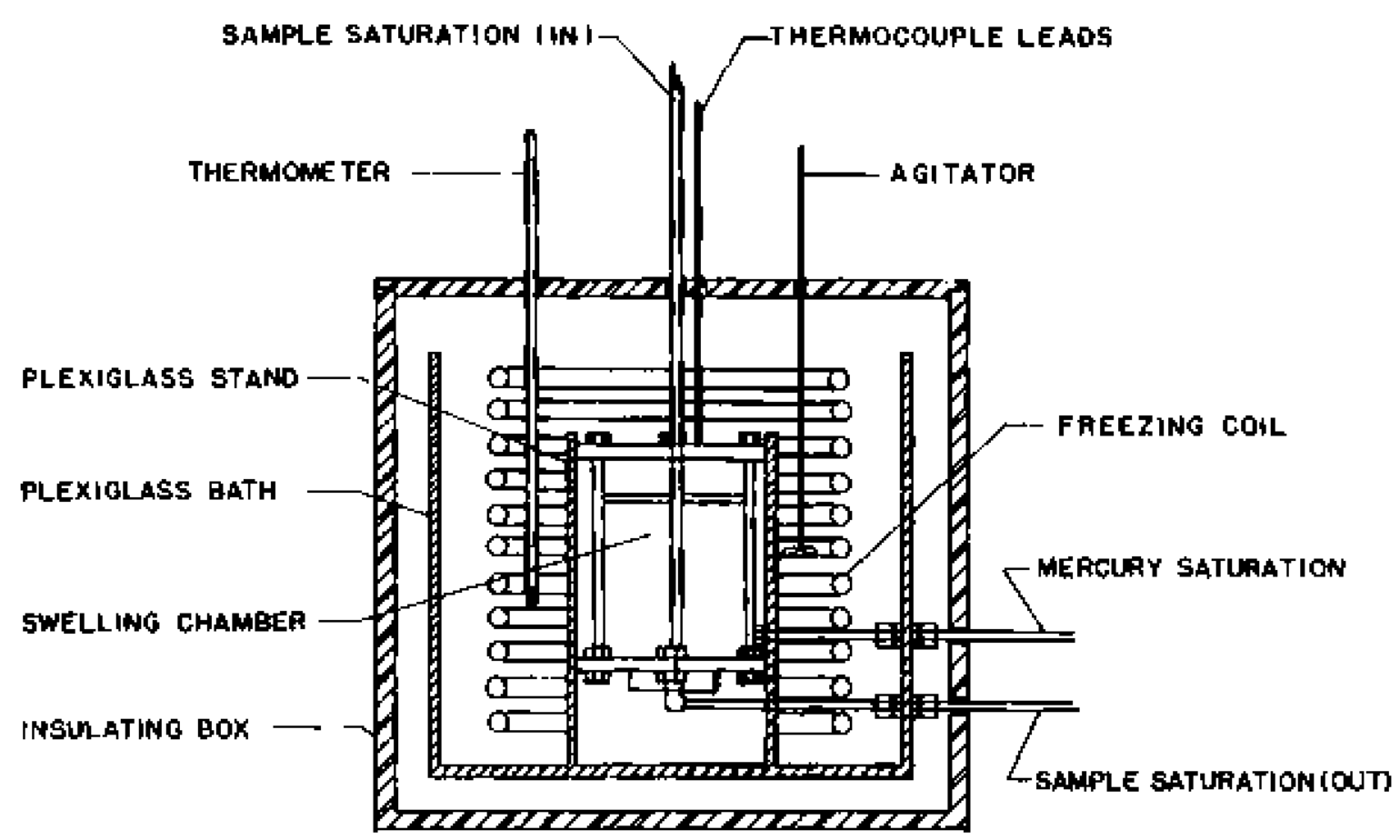

SECTIONAL VIEW OF ASSEMBLED SWELLING CHAMBER IN BATH 


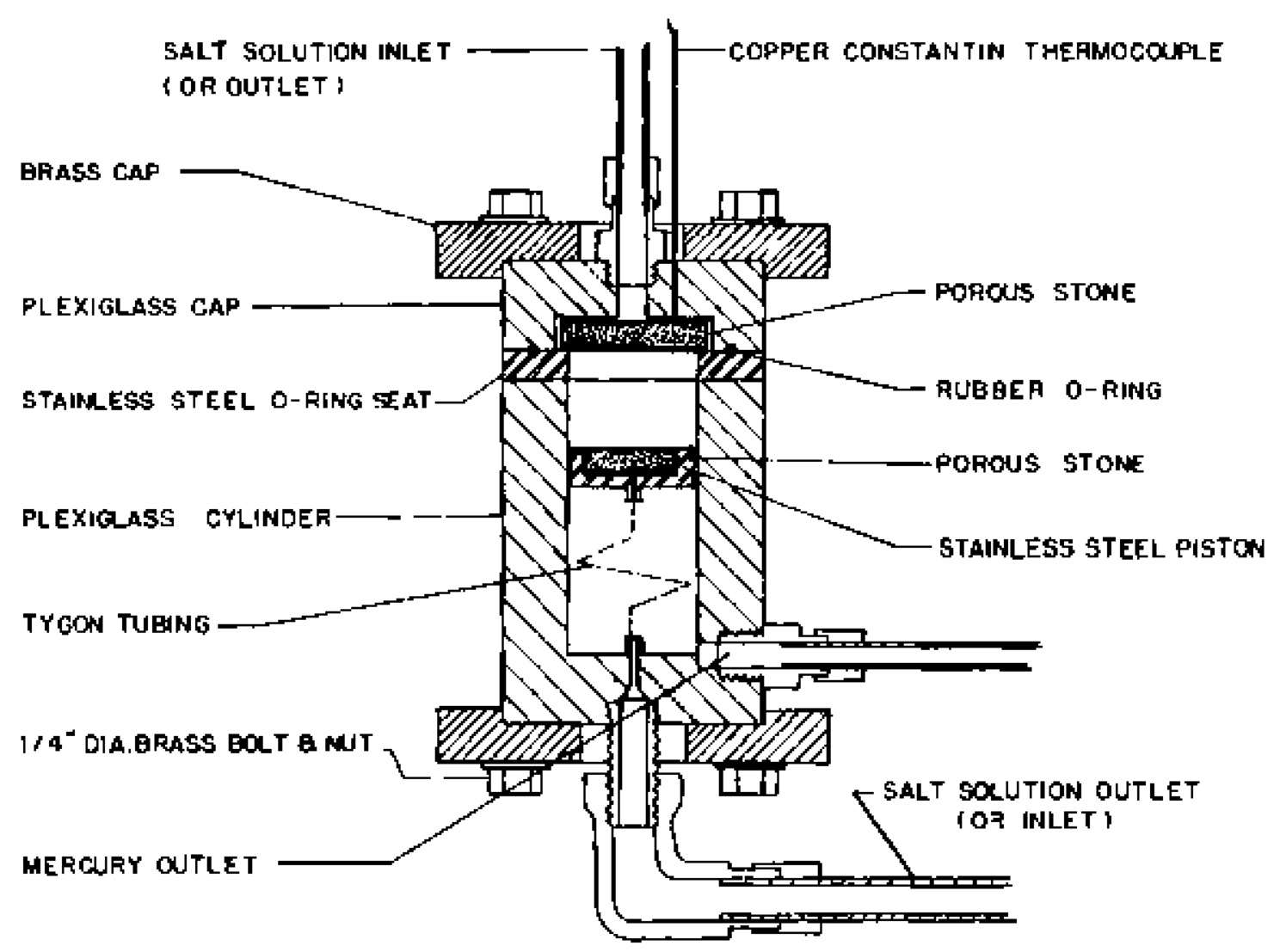

CROSS SECTION OF SWELLING CHAMBER 


\section{SCHEMATIC LAYOUT - SWELLING PRESSURE APPARATUS AND MEASUREMENT SYSTEM}

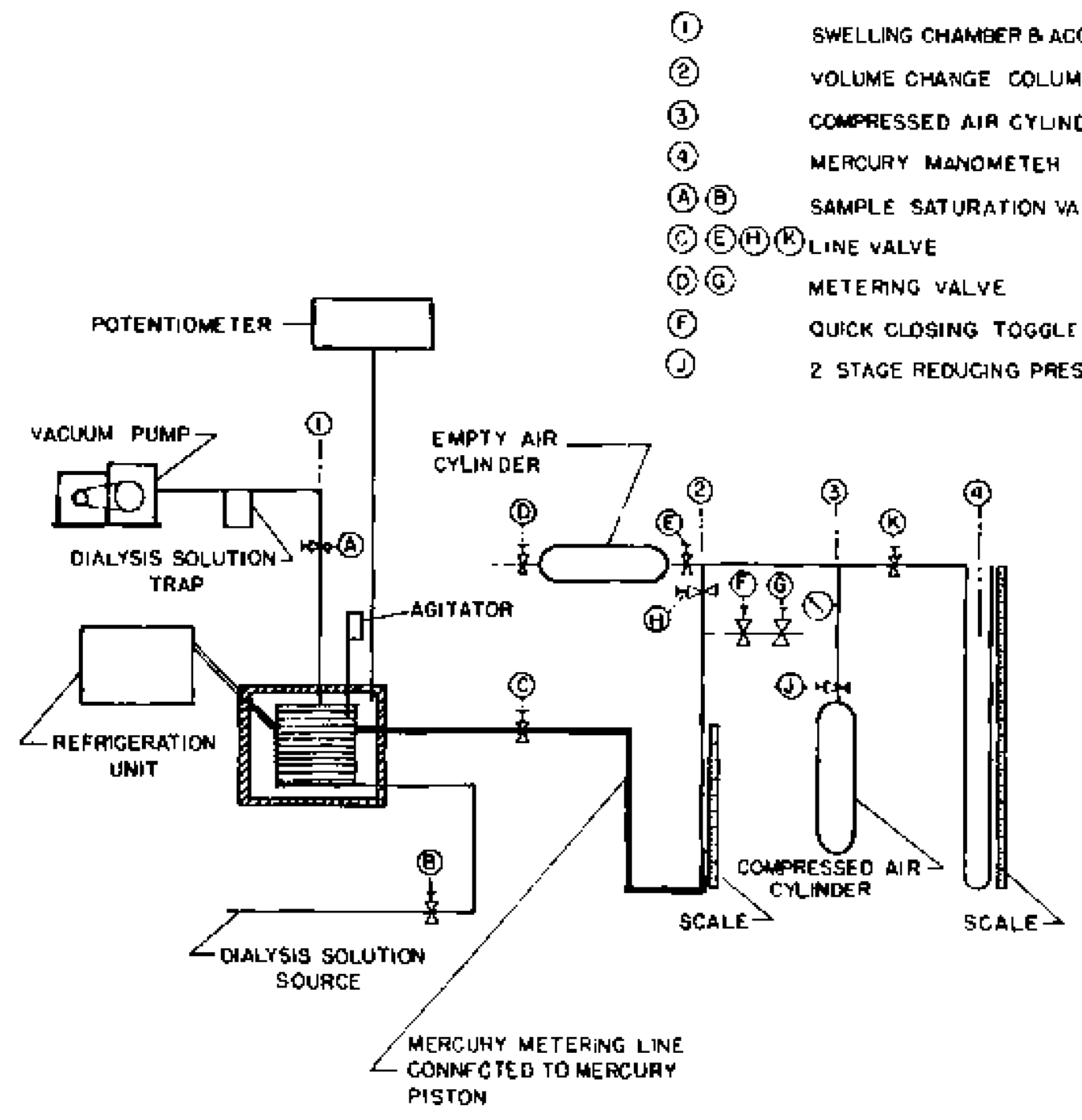

Figure 3 - SCHEMATIC LAYOUT - SWELLING PRESSURE APPARATUS AND MEASUREMENT SYSTEM 


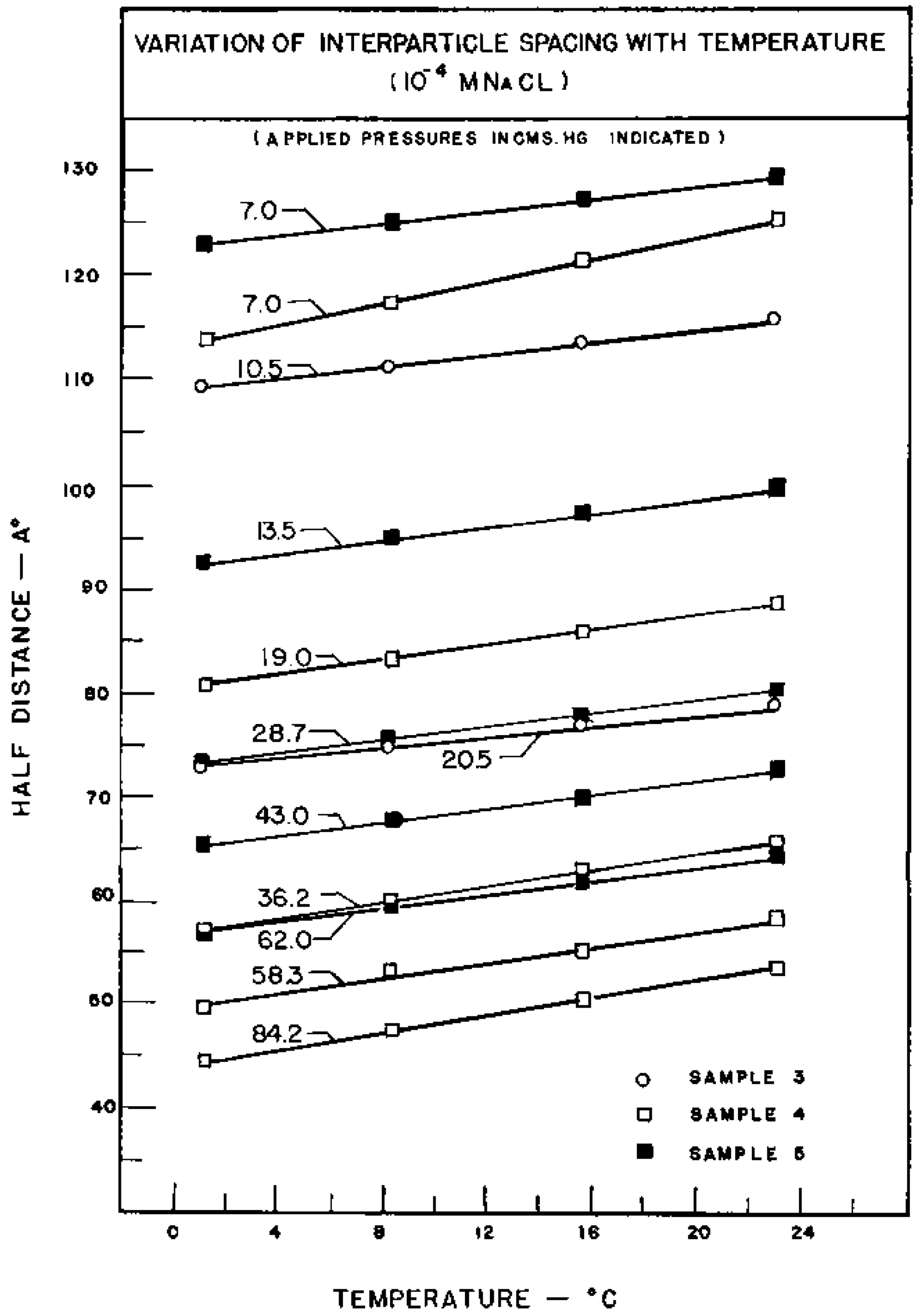

Fłgure + - VARIATION OF INTERPARTICLE SPACING WITH TEMPERATLRE ( LOW SALT CONCENTRATION) 


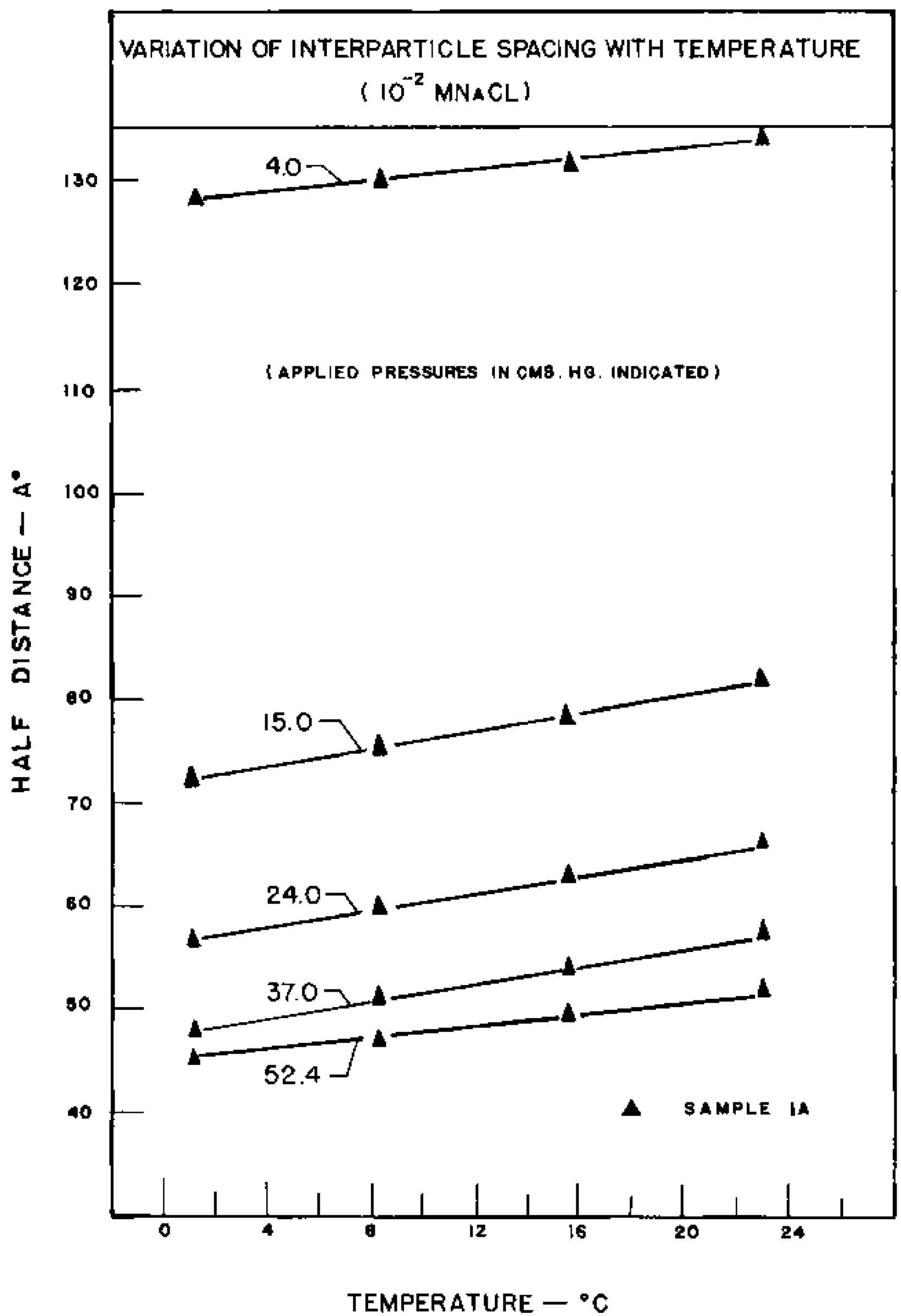

Figure 5 - VARIATION OF INTERPARTICLE SPACING WITII TEMPERATURE 


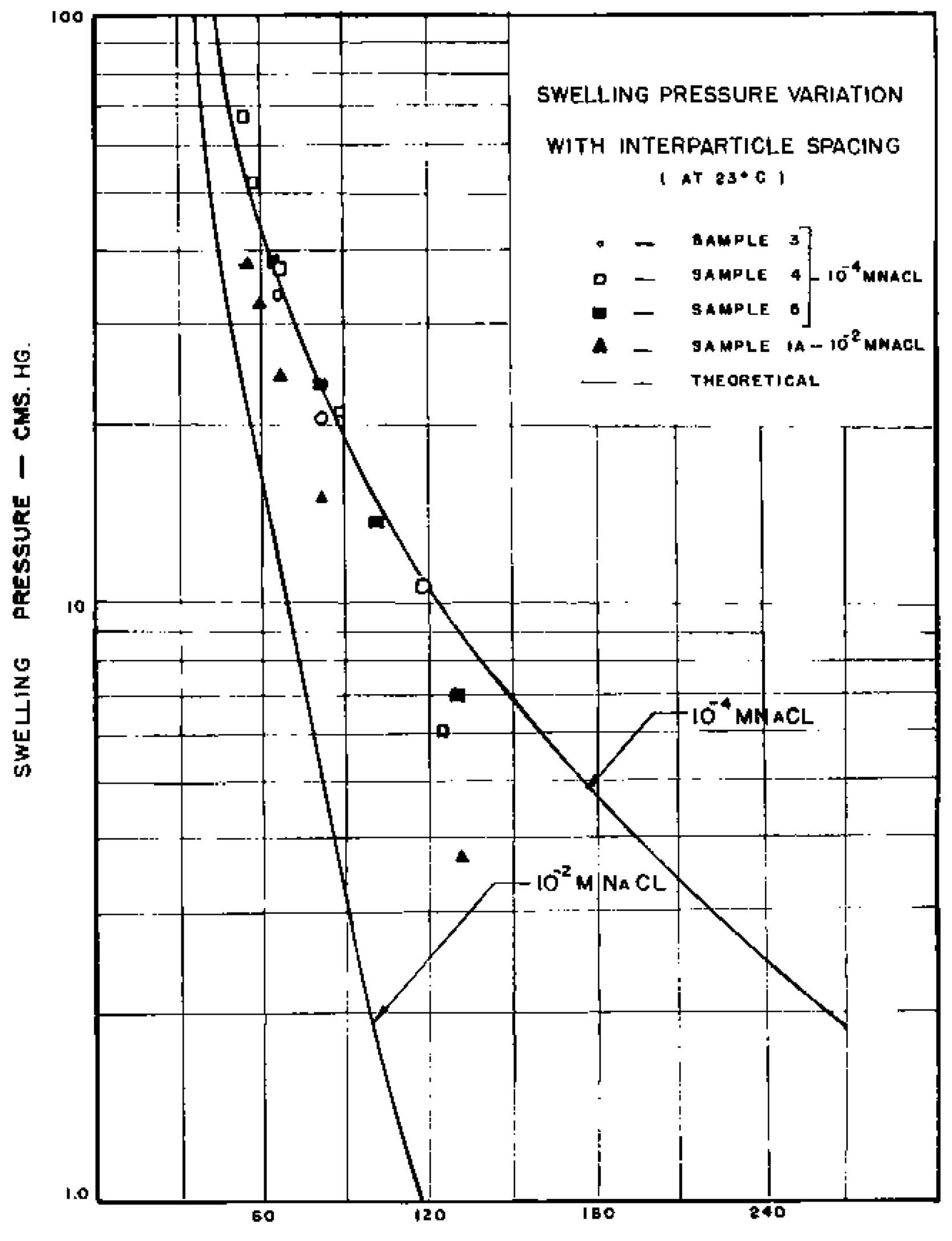

HALF DISTANCE - A*

Figure 6 - SWELLING PRESSURE VARIATION WITH INTERPARTICLE SPACING 


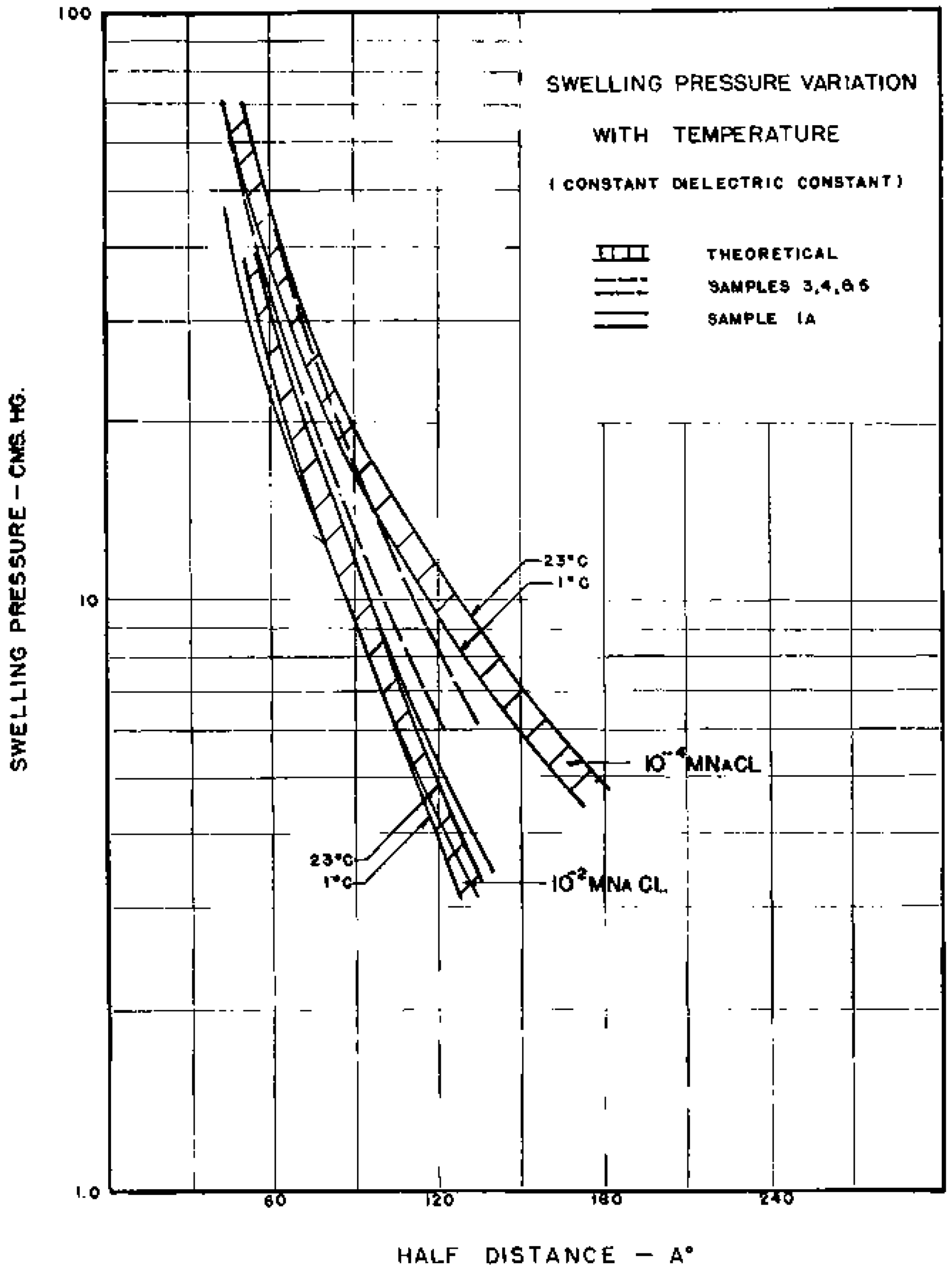

Figure 7 - SWELLING PRESSURE VARIATION WITH TEMPERATURE

(Constant Dielectric Constant) 


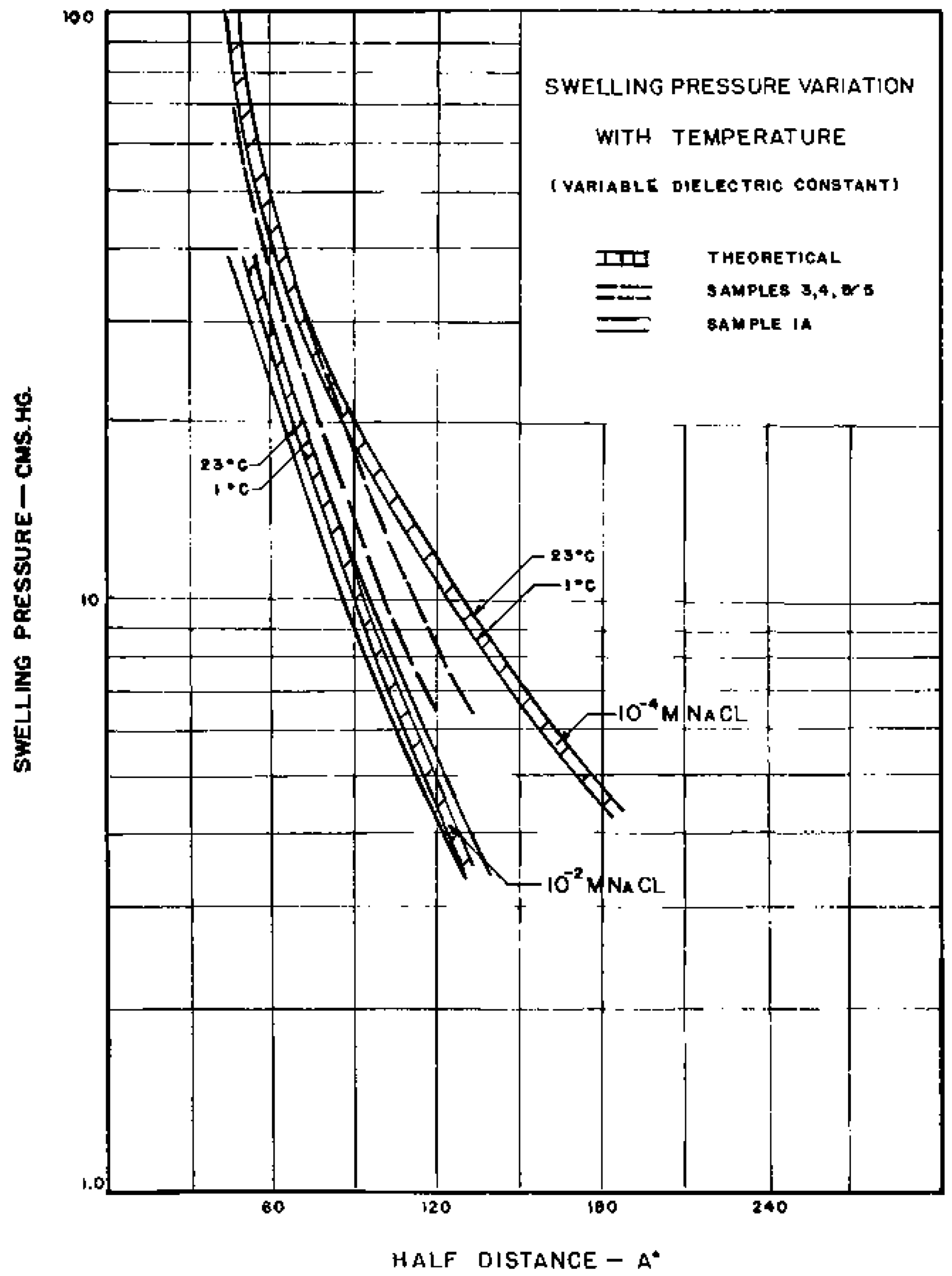

Figure 8 - SWELLING PRESSURE VARIATION

WITII TEMPERATURE

(Variable Dielectric Congtant) 